\title{
FINANCIAL LIQUIDITY OF AGRICULTURAL HOLDINGS
}

\author{
M. Dimitrova* \\ Department of Economics, Faculty of Economics, Trakia University, Stara Zagora, Bulgaria
}

\begin{abstract}
The liquidity of the agricultural holding makes it possible to establish to what extent it is possible for it to cover its liabilities in the near future. The company can focus on sticking to certain values of these indicators - these are values that according to the financial management of the company if achieved, it will mean that there will be no significant problems in terms of repayment of current obligations. The purpose of the research is after measuring the state of financial liquidity of agricultural holdings and capturing the trend, to analyze whether current ratios are enough for covering short-term expenses. The study has included representatives of the micro business in Bulgaria using survey and comparative analysis. The results reveal satisfactory levels of liquidity and managed to capture a descending trend comparing the levels of liquidity for the researched period.
\end{abstract}

Key words: liquidity, agricultural holdings, capital turnover, debt capital, short-term assets, liabilities, investments

\section{INTRODUCTION}

- Definition and basic concepts of the research.

The accounting information created in the agricultural holding reflects the overall economic activity. It is grouped by applying precisely defined rules and characterizes the property and its financial condition fully, objectively and reliably. This information is the subject of research and analysis, allows the determination of assessments of the results achieved and allows to direct the activities of the agricultural holding in the desired direction.(1)

In order to be more useful in the analysis, it is necessary to subject the accounting information to additional selection and differentiation, to compare it with indicators from previous reporting periods in order to detect certain trends in the development of the enterprise, to distinguish the impact of uncharacteristic processes and phenomena, as well as to measure the influence of various factors on the efficiency of the performed activity.

\footnotetext{
*Correspondence to: Marina Dimitrova, Department of Economics, Faculty of Economics, Trakia University, Stara Zagora 6000, Bulgaria, email: marina_12@abv.bg
}

Analysis and conclusions, mainly based on the data from the periodical accounts, are made both by the management of the enterprise and by its contractors (customers, suppliers, creditors, etc.), as well as by the tax control authorities and others.

The following tasks have been set:

- To reveal the state of liquidity in agricultural holdings;

To isolate the influencing factors by analyzing the measurement results obtained;

- To clarify the difference between liquidity and solvency.

The subject of the survey is randomly selected agricultural holdings who produce annual crops such as wheat, sunflower and etc. located in Bulgaria who represent the micro business. 49 of 70 respondents returned the survey with filled financial data so they were included in the research. Agricultural holding is a complicated unity of technical and organizingeconomic connections and relations, who define its internal mechanism of functioning as an independent business unit.(3)

The main concept of this research is to analyze the financial liquidity of the agricultural holding who produce annual crops 
based on types of liquidity, certain period and impacting factors.

Liquidity should be understood as the ability of the enterprise to service its current liabilities (payments) to creditors with available shortterm assets. Current payments mean the amount of short-term liabilities and the share of long-term liabilities due in the respective year. An important point in defining this ability is to clarify the question "When can an enterprise convert these assets into cash?" or it is the clarification of the degree of liquidity of the individual elements of the assets. (2)

Liquidity is often defined as the ability of a firm to repay its liabilities in the short term for example as short-term solvency. It is defined as a quantitative characteristic of its ability to repay its current liabilities with available current assets, which is equivalent to the ability of the enterprise's assets to be converted into cash. So liquidity is an indicator of the financial balance between assets and liabilities. Therefore, liquidity is analyzed on the basis of indicators that are quantitative characteristics of the firm's ability to repay its current liabilities with available current assets.

The liquidity of the company is determined by its ability to meet its current payments to creditors. Current payments are those related to short-term liabilities and repayments due for the respective period on the long-term available for the purpose short-term assets.

Liquidity can be viewed in a static and dynamic aspect.

Looking at it in a static aspect - it means the company at a specific time to have the necessary short-term assets to guarantee its current payments. Considering it in a dynamic aspect (long-term) liquidity implies taking into account the ability of the available assets of the enterprise to become liquid assets.

The first indicators of disruption in the liquidity management of enterprises are characterized by:

- difficulties in the supply of raw materials or deposition of raw materials, work in progress, production and goods;

- deterioration of the collection of receivables mainly from customers and suppliers;

- loss of alternative return on temporarily free cash;
- increase in indebtedness to banks and financial institutions mainly through working capital financing;

- difficult access to attracted capital;

- formation of liabilities to staff with a term of more than 1 month.(4)

The liquidity of a business organization depends on gathered receivables. The period of collection needs to be analyzed parallel to the period of payment of obligations. The period of gathering the receivables needs to be shorter than the period of paying the obligations. (5) Liquidity can be measured in different ways. One of the most accessible, but also the roughest is the so-called "Current ratio". The current ratio is the ratio of current assets to current liabilities. Under short-term assets, we understand most often cash, short-term investments, inventory capital and stocks, receivables from debtors and prepaid expenses. In agricultural holding also a short- term asset is the livestock, seeds in storage, planted seeds in land and fuel in storage. (1)

Short-term liabilities include various shortterm creditors, short-term loans, taxes due, insurance, etc. The comparison of these two quantities gives an idea not so much of the liquidity as of the solvency of the enterprise at a certain date, namely the date of the balance sheet.

The approach is too static because changes can start the day after the balance sheet is drawn up in both short-term assets and short-term liabilities. At first glance, it can be concluded that the ratio of 1: 1 is acceptable, but this shows the equality between short-term assets and short-term liabilities and the fact that the company cannot afford to increase its current assets. In such a situation, it is necessary to analyze the turnover of stored assets, also on whether there are components with short-term assets that are financed with short-term sources, with a shorter-term than the time for their transformation.

In such a situation, it is necessary to analyze the turnover of stocks, also on whether there are components with short-term assets that are financed with short-term sources, with a shorter term than the time for their transformation. It is also good to compare the terms of receivables from customers with those of the company's liabilities to suppliers. If the total liquidity ratio is less than one, no hasty 
conclusions should be drawn. The analyzes in the above guidelines are again positive, as well as an assessment of whether any of the components of short-term assets are not very fast turnover.

\section{- Types of liquidity}

The main liquidity indicators known in the economic literature are the ratios of total, quick, immediate and absolute liquidity. In the English literature, they are considered in close connection with the concept of working capital, which is defined as the difference between current assets and short-term (current) liabilities. Since current liabilities are those that must be repaid within the current reporting period, and current assets are those that can be most easily and quickly converted into cash within the current reporting period, working capital theoretically reflects the funds, which the company has at its disposal to carry out its production and commercial activities. In other words, working capital reflects that part of current assets that is financed by long-term funds, and therefore plays the role of a "shock absorber" that protects the company from short-term solvency problems.

Current liquidity - it is measured as the ratio between current (short-term) assets and current (short-term) liabilities. Where, Current Assets $=$ Various Debtors + Inventories + Cash-inhand + Cash-at-Bank + Receivables + Loans and Advances + Disposable Investments + Advance $\operatorname{Tax}$ and Current Liabilities = Creditors + Short-term Loans + Bank Overdraft + Cash Credit + Outstanding expenses + Provision for Taxation + Dividend payable.

Quick liquidity (or Acid-test ratio)- it is measured as the ratio between Quick Assets and Current Liabilities, where Quick Assets = Current Assets - Inventories - Prepaid Expenses.

Immediate liquidity- it is measured as the ratio between Short-term investments+ Cash and Short-term liabilities.

Absolute liquidity - it is measured between Cash and Bank balances and Short-term liabilities. It measures whether a firm can pay the current debts by using only the cash balances and bank balances.

\section{AIMS AND TASKS OF THE STUDY}

The aim of the study is to present the factors that impact liquidity on agricultural holdings that produce annual crops. A comparison between 3 following years is made to capture the trend. There has been made a survey to gather information about cash in hand, cash in bank, short-term investments, inventories, receivables, payables, loans, advance tax, provision of taxation and etc.

\section{SURVEY METHODS, MONITORING AND ANALYSIS OF THE TYPES OF LIQUIDITY IN AGRICULTURAL HOLDINGS}

All object who were included in the research had to respond to the following requirements: to be located in Bulgaria, to be a registered agricultural holding, to produce annual crops (such as wheat, sunflower and etc.) and to be representative of the micro business. According to article 3 paragraph 3 of the Law of Small and Medium Enterprises in Bulgaria a micro enterprise is who has no more than 10 employees and 3900000 BGN of yearly turnover and/or assets. The data is collected with personal research. The methods of the research are as following: the survey has been send to 70 random correspondents who are representatives of the micro business and 49 of them agreed to be included in the research. All participants provided voluntarily their yearly financial data, such as Current assets, Cash (in bank or in hand), Inventories, Prepaid expenses, Bank overdraft, Short- term loans, Receivables, Various debtors, Short-term investments in seed in land(where applicable) and etc. The collected financial data is for three years in order to obtain clear trend. An average calculation of financial states of different components of short-term assets and liabilities of the researched group of representatives has been made. After that a measurement for different type of liquidity gave the perspective of the captured trend. Analysis of the components of the formula has been made, in order to isolate the impacting factors that influence the trend.

\section{SURVEY RESULTS}

Using collected data, the following measurement of liquidity types has been made for a three year period:

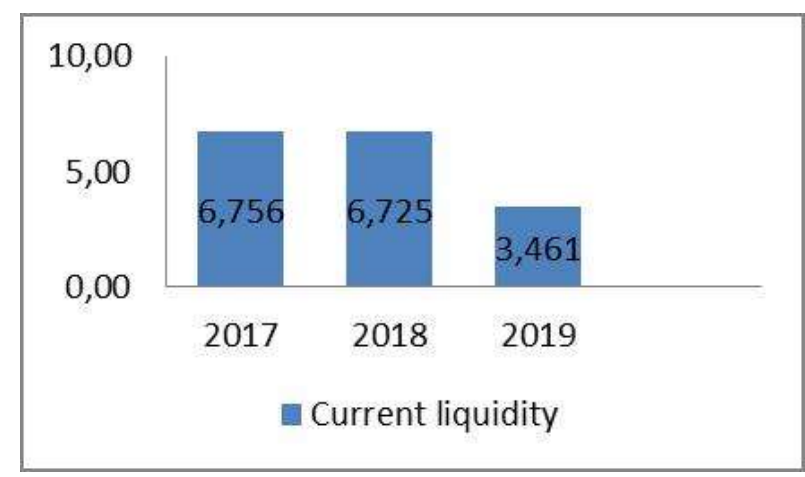

Figure 1. Current liquidity measurement ratio. 


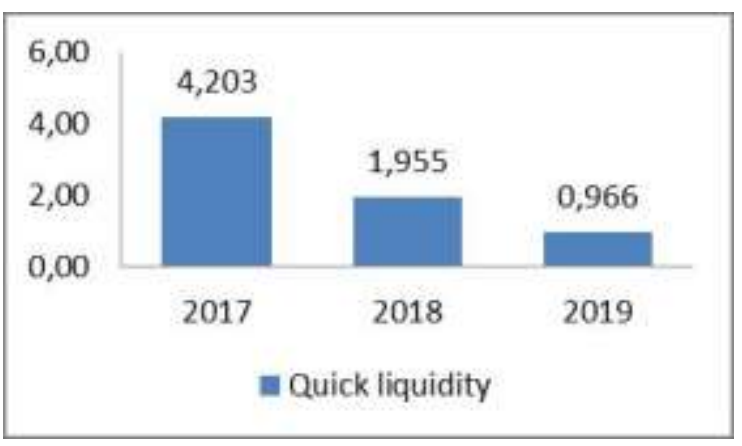

Figure 2. Quick liquidity measurement ratio.

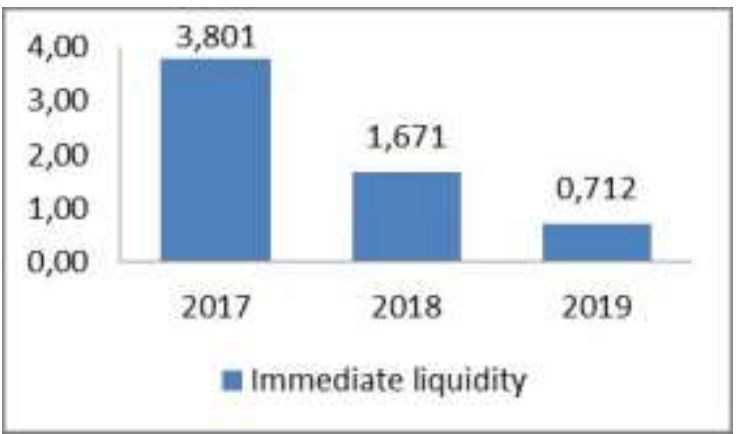

Figure 3. Immediate liquidity measurement ratio.

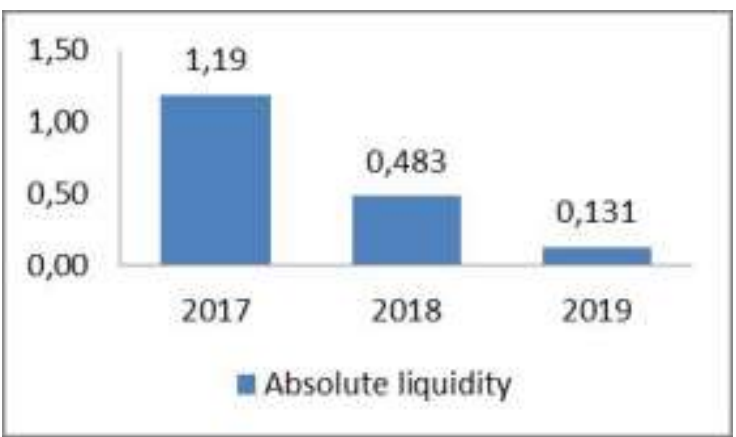

Figure 4. Absolute liquidity measurement ratio.

When comparing certain assets with short-term or current liabilities, it is normal to obtain a ratio of about one. If the coefficient is below one, for example, the amount of liabilities at the balance sheet date is greater than the funds to be covered, can be explained by the statement that some basic liabilities (tax payments, salaries, insurance, etc.) have a repayment period in the first half of the next month after they are issued, and the funds with which they will be covered will be received in the current month.

If the current liquidity ratio is equal to one or less than one, the possibility of financing part of the short-term assets through fixed capital should be monitored.

A coefficient greater than one at first glance does not give cause for concern, but again does not exclude the need for analysis in the areas listed above. It should be taken into account that the total liquidity ratio is specific to each company, as it is influenced by the cost and structure of assets, the specifics of the activity, etc. Each company is characterized by a typical liquidity ratio and the cause for concern is not so much the size of the ratio, but the deviations from it for one or another period. It is possible for several companies to have the same liquidity ratio at the same time, but their financial positions are completely different. In view of the outlined shortcomings of the total liquidity ratio in practice, a quick liquidity ratio is also calculated. It is the ratio of liquid assets to short-term liabilities. It is desirable that the liquidity ratios exceed one, which means that the company has more current assets than its liabilities at the balance sheet date. In this statement, the degree of risk that the company will fall into a state of inability to meet its obligations is too small.

In this survey, the trend is descending. We can monitor that in 2019 there is the lowest liquidity ratio in all types of liquidity in comparison with the other 2 years included in the analysis. Comparing the indicators that are included for the calculation of liquidity ratios, we notice the following deviations:

-the ratio of various debtors for 2019 is 15,5 times more compared to 2018 which impacts current and quick liquidity so this is the first impacting factor of the descending trend of liquidity that the research has managed to capture.

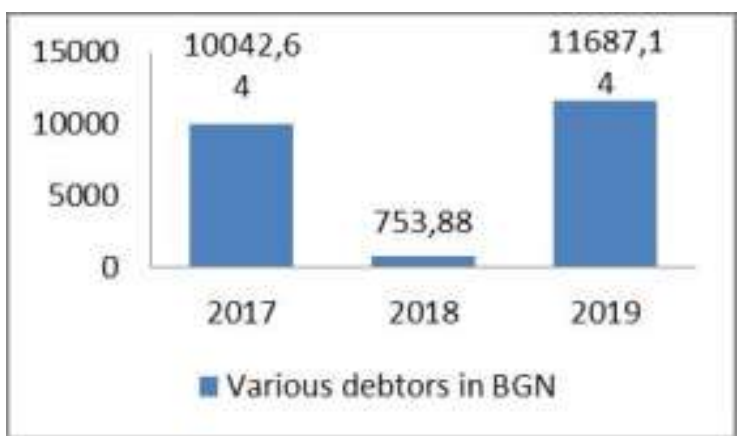

Figure 5. Various debtors data in BGN for three years.

-the ratio of short-term liabilities is 2,48 times higher than in 2018 and 2,50 higher than in 2017. It is a factor that is included in the denominator of the calculations. An ascending trend is monitored so we can conclude that companies' obligations have grown up in 2019 compared to previous two years and that is a factor which is impacting all types of liquidity. 


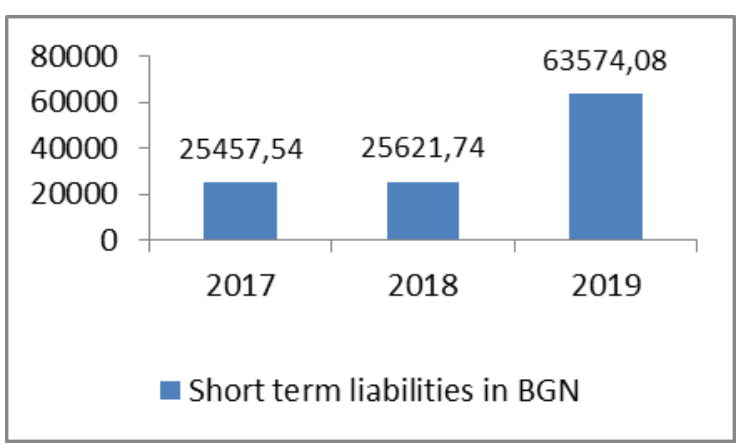

Figure 6. Short-term liabilities comparison between 3 years in BGN.

-due to the specification of their work, agricultural holdings who are the object of this research invest in seeds for the land crops. For this investment, they receive revenue after 3-6 months depending on the particular type of crop. The following comparison between the average rate of cash and the average rate of these investments for seeds in land gives the explanation why the absolute liquidity ratio is so low compared to the current, quick and immediate liquidity ratio. Companies who manufacture production in other economic sectors may be able to create their product in one minute for certain types of product for example but this is not possible for agricultural holdings. They "freeze" their money as long as the crop is able to be released to the market. This is impacting directly on absolute liquidity. All of our respondents had more assets invested in land for crops than in cash or bank.

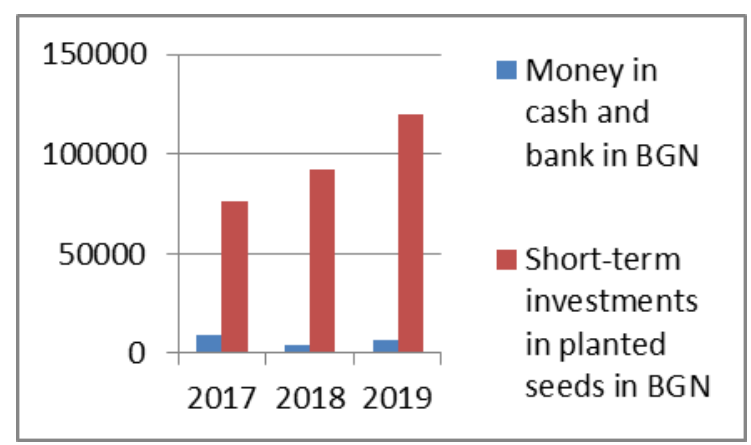

Figure 7. Comparison between money and shortterm investments in seeds planted in land in BGN for three years.

-the following influencing factors have been isolated:

- Intercompany indebtedness as an external impact factor.

- The ratio between investments in planted seeds and money as an internal impact factor.

-main differences between liquidity and solvency (1):
- $\quad$ as it has been already specified liquidity means to receive money at the moment of need, ie. the company's ability to meet its financial obligations in the short term. Solvency refers to the ability of a firm to have sufficient assets to meet its debts when they become payable.

- Liquidity is the potential of the company to fulfill its short-term obligations. On the other hand, solvency is the company's willingness to clear its long-term debts.

- Liquidity is how easily assets can be turned into money. Conversely, solvency is how well a company is maintained for a long time.

- The solvency of the company is determined by the solvency ratios, such as the debt / equity ratio, interest coverage, the ratio of fixed assets to net worth, and liquidity is measured by the ratios described above.

- Liquidity risk may affect the creditworthiness of the company. In contrast, the risk of solvency can lead to the bankruptcy of the company.

Both liquidity and solvency help agricultural holdings know whether a company is able to meet its financial obligations or not in a timely manner.

\section{MAIN CONCLUSIONS}

- $\quad$ The research has proved that in 2019 agricultural holdings in Bulgaria who represents micro business have more than twice lower liquidity compared to the previous two years.

- $\quad$ The levels of short -term liabilities and various debtors are ascending which also helps to low the liquidity ratio for 2019 compared to 2018 and 2017.

- The levels of current liquidity are higher than 1, so representatives at agricultural microbusiness in Bulgaria are capable of meeting their obligations in short-term.

In conclusion it has been clarified that intercompany indebtedness has increased in 2019 compared to previous 2 years. Companies maintain their solvency despite the fact that absolute liquidity is extremely low because cash is maintained in low levels due to the specific of the crops production.

\section{REFERENCES}

1. Slavova G., Management in Agricultural bussiness, 2014, Varna.

2. Stoyanov St., Financial Accountancy, 2013, Sofia. 
DIMITROVA M.

3. Terziyska R., Management in Agricultural holding, 2018, Sofia.

4. Andreeva D., Financial management of the enterprice and role of bussiness evaluation, 2012, Sofia
5. Andreeva D., Finansing of the bussiness organization, 2012, Sofia 